\title{
The Pectoral Branch Arising from the Subscapular Artery: Case Report of a Rare Variation
}

\author{
Jae-Hee Park, Jae-Ho Lee, In-Jang Choi \\ Department of Anatomy, School of Medicine, Keimyung University, Daegu, Republic of Korea \\ Email:anato82@dsmc.or.kr
}

How to cite this paper: Park, J.-H., Lee, J.-H. and Choi, I.-J. (2016) The Pectoral Branch Arising from the Subscapular Artery: Case Report of a Rare Variation. Forensic Medicine and Anatomy Research, 4 , 41-45.

http://dx.doi.org/10.4236/fmar.2016.44008

Received: December 19, 2016

Accepted: January 6, 2017

Published: January 9, 2017

Copyright $\odot 2016$ by authors and Scientific Research Publishing Inc. This work is licensed under the Creative Commons Attribution International License (CC BY 4.0). http://creativecommons.org/licenses/by/4.0/

\section{cC) (i) Open Access}

\begin{abstract}
Variations in the upper limbs are common and are the main causes for iatrogenic injury during invasive procedures. A rare division of the axillary artery was found on the left side of a Korean cadaver during an educational dissection. The subscapular artery originated from the second part of the axillary artery. And then it gave off an aberrant branch to the pectoralis major muscle, as pectoral branch. The author describes this previously unreported case and discusses its prevalence and the clinical implications.
\end{abstract}

\section{Keywords}

Axillary Artery, Subscapular Artery, Thoracoacromial Artery, Variation

\section{Introduction}

The axillary artery, the continuation of the subclavian artery, begins at the lateral border of the first rib, and after passing the lower margin of the teres major muscle, it becomes the brachial artery. The most frequent anatomic variations in this region are the persistent superficial brachial artery, branches of the axillary artery, and high division of the radial and ulnar arteries [1] [2]. As some variations in these regions are the main cause for technical failures during catheterization and interventional procedures, anatomical knowledge of these variations provides the essential basis for the safe and efficient performance [3] [4].

Arterial variations in the upper limbs are extremely diverse because of the use of different terminologies and criteria for classifying these variations [5]. Variations in the origin, branching, and course of the axillary artery have been frequently reported [5] [6] [7]. Some authors studied the branches of the axillary 
artery with large cases anatomical analysis and suggesting specified type of the axillary artery. In the article, we describe a pectoral branch of the thoracoacromial artery originated from the subscapular artery unlike any case reported previously. This case does not match any of the criteria in large-scale studies about arterial variations and thus has clinical implications during trans-arterial procedures.

\section{Case Report}

Variations in the arterial system were observed in the left upper limb of donated cadaver of a 53-year-old Korean male during an educational dissection. The immediate cause of death was cardiac arrest.

The axillary artery branched off the superior thoracic and thoracoacromial arteries in first and second parts, respectively. However, the subscapular artery was originated from the second part of the axillary artery, just below the pectoralis minor muscle. After continuing for $2.3 \mathrm{~cm}$ more, the subscapular artery gave off one branch supply the pectoralis major muscle, as the pectoral branch of the thoracoacromial artery (Figure 1). And then, the subscapular artery continued $1.7 \mathrm{~cm}$ more, divided into the circumflex scapular and thoracodorsal arteries. Other branches of the thoracoacromial artery were originated from the thoracoacromial artery. The pectoralis major muscle was innervated by the median and lateral pectoral nerves. In the right side, the thoracoacromial artery and their branches were originated from the second part of the axillary artery. Their subsequent courses were normal.

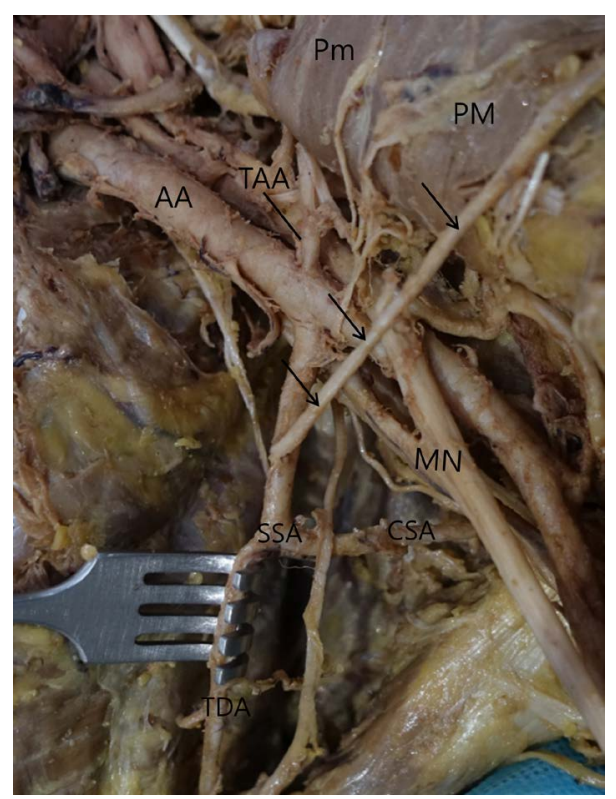

Figure 1. Photograph of the second part of the axillary artery (AA). The subscapular artety (SSA) gave off the pectoral branch (arrows). CSA, circumflex scapular artery; MN, median nerve; PM, pectoralis major; Pm, pectoralis minor; TAA, thoracoacromial artery; TDA, thoracodorsal artery. 


\section{Discussion}

Ugliettaand Kadir [8] reported variations in the major arteries of upper extremities to be present in $11 \%-24 \%$ of people. It has been frequently reported that the thoracoacromial artery arose from the first part of the axillary artery, in $29.8 \%$ of cases by Huelke [7] and $85.7 \%$ of cases by De Garis and Swartley [8]. However, the thoracoacromial artery from the lateral thoracic artery was absent in these studies. De Garis and Swartley [8] reported a thoracoacromial artery from the subscapular artery in $1.2 \%$ of cases. Based on the review of our previous results [9], the origin of the thoracoacromial artery was reviewed and presented in $\mathrm{Ta}$ ble 1. Our data demonstrated that common origin of the thoracoacromial artery and the subscapular artery frequently accompany the lateral thoracic artery. In present case, we showed a pectoral branch of the thoracoacromial artery arose from the subscapular artery. Other branches of the thoracoacromial artery arose from the thoracoacromial trunk normally. This aberrant pectoral branch may be an additional branch supplying the pectoralis major muscle. Our case did not match any previously reported patterns, moreover independent pectoral branch from the subscapular artery has not been reported in any literatures. This vascular pattern may influence the blood supply for the pectoralis major muscle because of relatively distal origin of the pectoral branch from the axillary artery. This hemodynamic change should be confirmed further.

Pandey and Shukla [10] studied about the origin level and pattern of the thoracoacromial trunk variations and divided these variations into three groups. In the first group, the common trunk was absent but deltoacromial and clavipectoral sub-trunks arose directly from the second part of the axillary artery. In the second group, only the clavicular branch independently arose from the second part of an axillary artery and the remaining three were arising from thoracoacromial trunk. In the third group, all classical branches of thoracoacromial trunk arose directly from the second part of the axillary artery without any common trunk. Based on these criteria, to the best of our knowledge, this is the first report to introduce a subscapular artery containing the pectoral branch of the thoracoacromial artery, the circumflex scapular artery, and thoracodorsal artery.

This arterial variation of the axilla can be explained through the persistence, enlargement and differentiation of parts of the initial network which would normally remain as capillaries or even regress [5]. The axillary artery had been

Table 1. Origin of the thoracoacromial artery.

\begin{tabular}{cccc}
\hline Origin of the thoracoacromial artery & Huelke & De Garis and Swartley & This study \\
\hline Direct from first part AA & $29.8 \%$ & $85.7 \%$ & $1.6 \%(2 / 120)$ \\
Direct from second part AA & $68.5 \%$ & $12.1 \%$ & $98.4 \%(118 / 120)$ \\
From the SSA & - & $1.2 \%$ & $3.2 \%(4 / 120)$ \\
Common stem with SSA & - & - & $0.8 \%(1 / 120)$ \\
Common stem with SSA and LTA & - & - & $2.4 \%(3 / 120)$ \\
\hline
\end{tabular}


used for interventional routes and non-invasive procedures, especially, central venous line [1] [2]. In surgical procedure, knowledge of the axillary artery and the pectoralis major was essential for approach in arm pit injury or breast cancer surgery [5]. Therefore, awareness of these variations may be useful servant for many clinicians and be important to prevent complications during or after surgical interventions and diagnostic procedures.

\section{Conclusion}

In present report, a rare case with pectoral branch originated from the subscapular artery was introduced. Clinical procedures in pectoral and axillary regions require accurate knowledge of the normal and variant anatomy of the axillary artery. To confirm the pattern of this variation, radiological study should be performed in larger cases.

\section{Conflict of Interest}

The authors declare that they have no conflict of interests.

\section{Acknowledgements}

This study was supported by grants of the Basic Science Research Program through the National Research Foundation of Korea (NRF) funded by the Ministry of Education (NRF-2014R1A6A3A04058057).

\section{References}

[1] Jurjus, A.R., Sfeir, R.E. and Bezirdjian, R. (1986) Unusual Variation of the Arterial Pattern of the Human Upper Limb. The Anatomical Record, 215, 82-83.

https://doi.org/10.1002/ar.1092150112

[2] Uglietta, J.P. and Kadir, S. (1989) Arteriographic Study of Variant Arterial Anatomy of the Upper Extremities. Cardiovascular and Interventional Radiology, 12, 145148. https://doi.org/10.1007/BF02577379

[3] Deligonul, U., Gangliani, G., Kern, M.J. and Vandormael, M. (1988) Percutaneous Brachial Catheterization: The Hidden Hazard of High Brachial Artery Bifurcation. Catheterization and Cardiovascular Diagnosis, 7, 111-114. https://doi.org/10.1002/ccd.1810140110

[4] Yokoyama, N., Takeshita, S., Ochiai, M., Koyama, Y., Hoshino, S., Isshiki, T. and Sato, T. (2000) Anatomic Variations of the Radial Artery in Patients Undergoing Transradial Coronary Intervention. Catheterization and Cardiovascular Interventions, 49, 357-362. https://doi.org/10.1002/(SICI)1522-726X(200004)49:4<357::AID-CCD1>3.0.CO;2-Z

[5] Rodríguez-Niedenführ, M., Burton, G.J., Deu, J. and Sañudo, J.R. (2001) Development of the Arterial Pattern in the Upper Limb of Staged Human Embryos: Normal Development and Anatomic Variations. Journal of Anatomy, 199, 407-417. https://doi.org/10.1046/j.1469-7580.2001.19940407.x

[6] Hitzrot, J.M. (1901) A Composite Study of the Axillary Artery in Man. Johns Hopkins Hospital Bulletin, 12, 136-145. 
[7] Huelke, D.F. (1959) Variation in the Origins of the Branches of the Axillary Artery. The Anatomical Record, 135, 33-41. https://doi.org/10.1002/ar.1091350105

[8] De Garis, C.F. and Swartley, W.B. (1928) The Axillary Artery in White and Negro Stocks. The American Journal of Anatomy, 41, 353-397.

https://doi.org/10.1002/aja.1000410208

[9] Lee, H., Kim, H.T., Lee, J.H. and Choi, I.J. (2015) Low Frequency of the Lateral Thoracic Artery Originating from the Thoracoacromial Artery. Surgical and Radiological Anatomy, 37, 319-320. https://doi.org/10.1007/s00276-014-1363-x

[10] Pandey, S.K. and Shukla, V.K. (2007) Anatomical Variations of the Cords of Brachial Plexus and the Median Nerve. Clinical Anatomy, 20, 150-156. https://doi.org/10.1002/ca.20365

\section{Submit or recommend next manuscript to SCIRP and we will provide best} service for you:

Accepting pre-submission inquiries through Email, Facebook, LinkedIn, Twitter, etc.

A wide selection of journals (inclusive of 9 subjects, more than 200 journals)

Providing 24-hour high-quality service

User-friendly online submission system

Fair and swift peer-review system

Efficient typesetting and proofreading procedure

Display of the result of downloads and visits, as well as the number of cited articles

Maximum dissemination of your research work

Submit your manuscript at: http://papersubmission.scirp.org/

Or contact fmar@scirp.org 